\title{
Study the Influence of UV-Irradiation on the Photo Stability of Pure and Plasticized Poly (4-Vinyl Biphenyl) in Solid Films
}

\author{
Khalid Essa Al Ani ${ }^{*}$, Afrah Essa Ramadhan², Suha Khanfar ${ }^{3}$ \\ ${ }^{1}$ Department of Pharmaceutical Sciences, Faculty of Pharmacy, Jadara University, Irbid, Jordan \\ ${ }^{2}$ Department of Industrial Chemistry, Institute of Technology, Baghdad, Iraq \\ ${ }^{3}$ Department of Chemistry, Faculty of Science, Hashemite University, Zarka, Jordan \\ Email: *khalidalani44@yahoo.com, *k.alani@jadara.edu.jo
}

How to cite this paper: Al Ani, K.E., Ramadhan, A.E. and Khanfar, S. (2017) Study the Influence of UV-Irradiation on the Photo Stability of Pure and Plasticized Poly (4-Vinyl Biphenyl) in Solid Films. Materials Sciences and Applications, 8, 1027-1052. https://doi.org/10.4236/msa.2017.813075

Received: September 7, 2017

Accepted: December 11, 2017

Published: December 14, 2017

Copyright $\odot 2017$ by authors and Scientific Research Publishing Inc. This work is licensed under the Creative Commons Attribution International License (CC BY 4.0).

http://creativecommons.org/licenses/by/4.0/

\begin{abstract}
The effect of UV irradiation and blending with phthalate and terephthalate plasticizers on the photo-stability of Poly (4-vinyl biphenyl) was studied at different intervals of irradiation time and in presence of air. The increase in irradiation time on the photodegradation of polymer thin films caused a change in the intensity and shape of the fluorescence band. It has been found that the stability of the polymer decreases with the increase of irradiation time, and to increases with the increase of the amount of added phthalate and terephthalate plasticizers, which is evidence of polymer photodegradation. The FT-IR spectra of irradiated pure and blended polymer with phthalate and terephthalate plasticizers showed a decrease in some absorption bands and increase in the other bands, this is also another factor for the occurrence of photo degradation of the irradiated polymer. The increase in the intensity of absorption of carbonyl and hydroxyl region, indicates a possible photogegradation of polymeric chains and the formation of alcohols, aliphatic ketones and to the increase in the number of $(\mathrm{C}=\mathrm{C})$ that resulted from hydrogen abstraction during chains-scission.
\end{abstract}

\section{Keywords}

Excimer Fluorescence, Photodegradation Kinetics, Phthalate Plasticizers, Poly (4-Vinyl Biphenyl), UV-Irradiation

\section{Introduction}

Polymer degradation is very important aspect due to the environmental research and their use in industry. The photogegradation of polystyrene (PS) and substi- 
tuted polystyrene (SPS) is of interest with respect to both the preparation of new polymers and to the stability of these polymers towards UV irradiations. However, since polystyrene (PS) and substituted polystyrene (SPS) were found to degrade easily upon exposure to light energy, several mechanisms were proposed but a totally consistent theory is yet to be agreed upon, due to the complexity of the photodegradation processes that yield different photo products [1] [2]. The nature of photo products resulted from exposure of polymer chains to light energy was found to depend on the substituted group in the styrene chromophores, and to the environment of degradation [3] [4] [5] [6]. The photodegradation of polymeric chains in presence of air is started by the formation of excited chromophores are formed and then other process such as photo-oxidation, chain scission and cross linking take place [7] [8].

It has been suggested two mechanisms for the photo-oxidation of polymeric structures; the first is the photoreaction that is based on the dissociation of excited peroxide macro radicals, leading to the formation of water and carbon dioxide molecules; the second mechanism is hydroperoxides mechanism, which is to form the $\left(\mathrm{RO}_{2}^{*}\right)$ radicals that reacts with the polymer structures to produce hydroperoxides radicals. A subsequent $(\mathrm{ROOH})$ decomposition results in the scission of polymeric chains and the formation of high molecular oxidation products such as carbonyl, alcohols and ethers [9] [10] [11] [12]. Photogegradation of polymeric chains in presence of air is triggered by the formation of peroxy free radicals, which degraded the polymeric structures through a series of chemical reactions, which lead to chain scissions and cross linking in the polymeric back bone. It was found that the mechanism of photodegradation of polystyrene and substituted polystyrene depends upon the mobility of free radicals in polymeric matrix, and their bimolecular combination [13]. As a result of decomposition of irradiated chromophores, Hydrogen radicals are formed, and they diffuse through the polymer matrix and finally initiate a free radical decomposition of polymer chains [14] [15] [16]. The photo-oxidation mechanism of PS chromophores in solid films is dependent upon the rate of oxygen diffusion into the polymer matrix, and to the formation of charge transfer complexes between polymer structures and oxygen molecules [17]. The photo-oxidation process depends on the reactivity of the formed polymeric radicals with oxygen molecules and to the diffusion process of oxygen into polymeric matrix. The combination of the formed micro-radicals will lead to the cross-linking. As a result of the photo-oxidation of polymeric chains, a number of different photoproducts are reported [18]-[24]. Hydroperoxides, carbonyl and hydroxyl compounds were the main products that have been reported on the bases of IR and UV-visible analysis [4] [5].

Electrophilic substitution is a general route for preparation of ring substituted polystyrene. It has been reported that photodegradation of most of substituted polystyrene are more easily photodegradable than polystyrene, owing to the weak bonds in substituted polystyrene structures. The studies of photodegrada- 
tion of ring substituted polystyrene have showed that degradation characteristics are sensitive to the nature of substituents, in particular, electron-withdrawing groups $(\mathrm{Cl}$ and $\mathrm{Br})$ that tend to reduce the stability of polymeric chains, largely by producing depolymerization radicals [18] [20]. On the other hand, fluoroatom substitution in phenyl ring in the polymeric chromophore tends to stabilize the polymer towards irradiations [18] [19] [20] [21].

It should be pointed out that polymeric additives were found to accelerate the radiation-induced degradation of polystyrene and substituted polystyrene [9] [25]. Phthalate and terephthalate as additives to substituted polystyrene causes an increase in its flexibility, but increase the stability of the polymeric chains [26] [27]. It was also found that the photo-stability of polystyrene was reduced by the addition of bromine-containing flame retardants, carbonyl group, or poly vinyl acetate, and appeared to depend upon the chemical structure of the polymeric additives [28]-[32]. It was found that the increase in the amount of doped plasticizers decrease the stability of polymeric chains and the increase in irradiation time of the UV-light causes also an increase in the efficiency of photodegradation process [33]-[39]. In many recent studies, it was found that blending with phthalate plasticizers were more efficient in increase in the photodegradation of polymeric chains than blending with terephthalate plasticizers [30] [31] [32].

The efficiency of photodegradation of polystyrene and substituted polystyrene was found to increase with increase in exposure times and to increase with the increase in the added mass of added plasticizers [33]-[39]. The changes in the average molecular weight in photo-oxidized PS were produced as consequences of chain dissociation by Norrish Type II reaction [34]. Phthalate plasticizers were more efficient in the increase in the photodegradation of irradiated polymeric chromophores in solid films [31] [32].

According to the reported work on substituted polystyrene, no work has been reported on the photodegradation of pure and plasticized poly (4-vinyl biphenyl) in solid films. It was found to be used in binding to other polymers, such as poly ( $\alpha$-methylstyrene) and poly (triarylamine). The binding polymers are normally used to improve film formation in a large area uniformly and to help the poly (triarylamine) to form a stronger binding between source/drain electrodes onto dielectric layer in the active channel material of an organic thin film transistor [40].

In the present work, the photodegradation of irradiated poly (4-vinyl biphenyl) films, and the effects of blending with phthalates and terephthalate plasticizers on the photo-stability were investigated with the following aims:

1) To investigate the possible influence of ring substitution on the mechanism of photochemical reaction of irradiated poly (4-vinyl biphenyl), (PVBP) films and also to compare its photo-stability with that of polystyrene and other substituted polystyrene.

2) To study the effect of blending poly (4-vinyl biphenyl), (PVBP) with phthalates and terephthalate plasticizers on the photo-stability, and to select the 
best polymeric additive that can cause less photodegradation effect on the irradiated polymeric films.

3) To apply Al Ani-Hawi relation [30], in order to evaluate some kinetic parameters, such as photo quenching rate constant and quenching efficiencies of irradiated pure and blended polymer films.

The photodegradation processes of the exposed polymer films for different intervals of time have been characterized by UV-visible, fluorescence and FT-IR spectroscopic techniques.

\section{Experimental}

\subsection{Materials}

The sample of poly (4-vinyl biphenyl), (PVBP) was obtained from Sigma Aldrich Chem. Co. The average molecular weight for the polymer is 115,000 , and was used as received. Dichloroethane (DCM) solvent as a spectroscopic grade was obtained from Fluka GMBH, and showed no absorption or emission in the range of $293-550 \mathrm{~nm}$. The used plasticizers, dimethyl terephthalate (DMT), diethyl terephthalate (DET), dioctyl terephthalate (DOT), dibutyl phthalate (DBP), and dioctyl phthalate (DOP), were obtained from Sigma Aldrich Co., and were used without further purifications. These were of high purity of about (99.8\%), and were found to give no detectable absorption in the range $(265-400 \mathrm{~nm})$.

\subsection{Preparation and Irradiation of Plasticized Polymeric Solid Films}

Poly (4-vinyl biphenyl) thin films with thickness of approximately $0.02 \mathrm{~mm}$ were prepared by solution casting of the polymer in spectrograde dichloroethane on a spectroscopic window (quartz plate of $1.0 \mathrm{~mm} \times 20 \mathrm{~mm}$ diameter). Moreover, about $0.02 \mathrm{~mm}$ thick poly (4-vinyl biphenyl) - plasticizer films, containing different $\mathrm{wt} \%$ plasticizers were prepared by solution casting [polymer + $(5-15$ wt\%) added plasticizer], using spectrograde dichloroethane solvent. These films were used as to gain better insight into the possibility of photodegradation of the polymer during irradiation. The films were dried in a vacuum oven at $293 \mathrm{~K}$ for 6 hours, as to ensure the complete removal of solvent traces [41].

Irradiation processes of solid films were exposed to different intervals of irradiation time in air, from (0 - $120 \mathrm{~min})$, Using JASCO- Spectrofluorometer with a built in Hydrogen-Xenon lamp (6808-J007A-model number ESC-333) supported with monochromator of holographic grating with 1800 groves $/ \mathrm{mm}$. All solid films were exposed to the same rate of irradiation intensity for different intervals of irradiation time in air, from $(0.0-120 \mathrm{~min})$. The intensity of incident radiation was $\left(4.9 \mathrm{~mW} / \mathrm{cm}^{2}\right)$, and the distance between light source and samples was $(5 \mathrm{~cm})$.

\subsection{Absorption and Fluorescence Spectra Measurements}

UV-Vis absorption spectra of non-irradiated PVBP and the used plasticizers 
were obtained using an Agilent $8453 \mathrm{UV}$-Vis spectrophotometer.

Fluorescence spectra of pure and blended polymer solid films were recorded on JASCO-FP 6500 Spectrofluorometer. The parameters were constant for all measurements, and the excitation wavelength was $288 \mathrm{~nm}$. The emission wavelength range was 290 - $550 \mathrm{~nm}$, and all fluorescence spectra for solid films were obtained using a thermostated solid sample holder at $298 \mathrm{~K}$.

\subsection{FT-IR Spectroscopy}

Infrared spectra were collected using a NICOLET-MAGNA-IR-560 spectrometer, (the manufacturer Thermo Nicolet Corporation, Madison, USA). The working wavenumber range of the spectrometer was from $\left(4000\right.$ to $\left.500 \mathrm{~cm}^{-1}\right)$ at $\left(4 \mathrm{~cm}^{-1}\right)$ optical resolution and 3 scan repetitions per analysis. The $F T-I R$ spectra were recorded for the irradiated and the non-irradiated polymer films, whereas the transmittance was plotted as function of the wavenumber.

\section{Results and Discussion}

\subsection{The Absorption Spectra of Poly (4-Vinyl Biphenyl) and Phthalate and Terephthalate Plasticizers}

The UV-absorption spectra of both, poly (4-vinyl biphenyl), the phthalate and terephthalate plasticizers in dichloroethane solutions at room temperature are shown in Figure 1(a) and Figure 1(b) respectively.

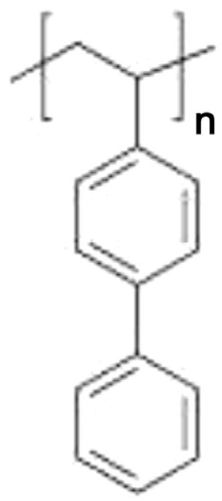

Poly (4-vinyl biphenyl) molecular structure.

As can be seen from Figure 1(a), the absorption spectrum of poly (4-vinyl biphenyl) was found to absorb radiation in the UV-region in the range of (270 $330 \mathrm{~nm}$ ) with a maxima at $(288 \mathrm{~nm})$, approximately similar to those of polystyrene and other substituted polystyrenes. The small changes in the position and the shape of absorption spectrum may be attributing to the chemical structure and the position of substitution in phenyl ring [6]. The excitation wavelength that has been used for PVBP films was $288 \mathrm{~nm}$ for fluorescence spectra and FT-IR spectra measurements. Both phthalate and terephthalate plasticizers absorb radiation in the range of $(215-262 \mathrm{~nm})$ and are far away from the absorption region of PVBP films, as shown in Figure 1(b). 


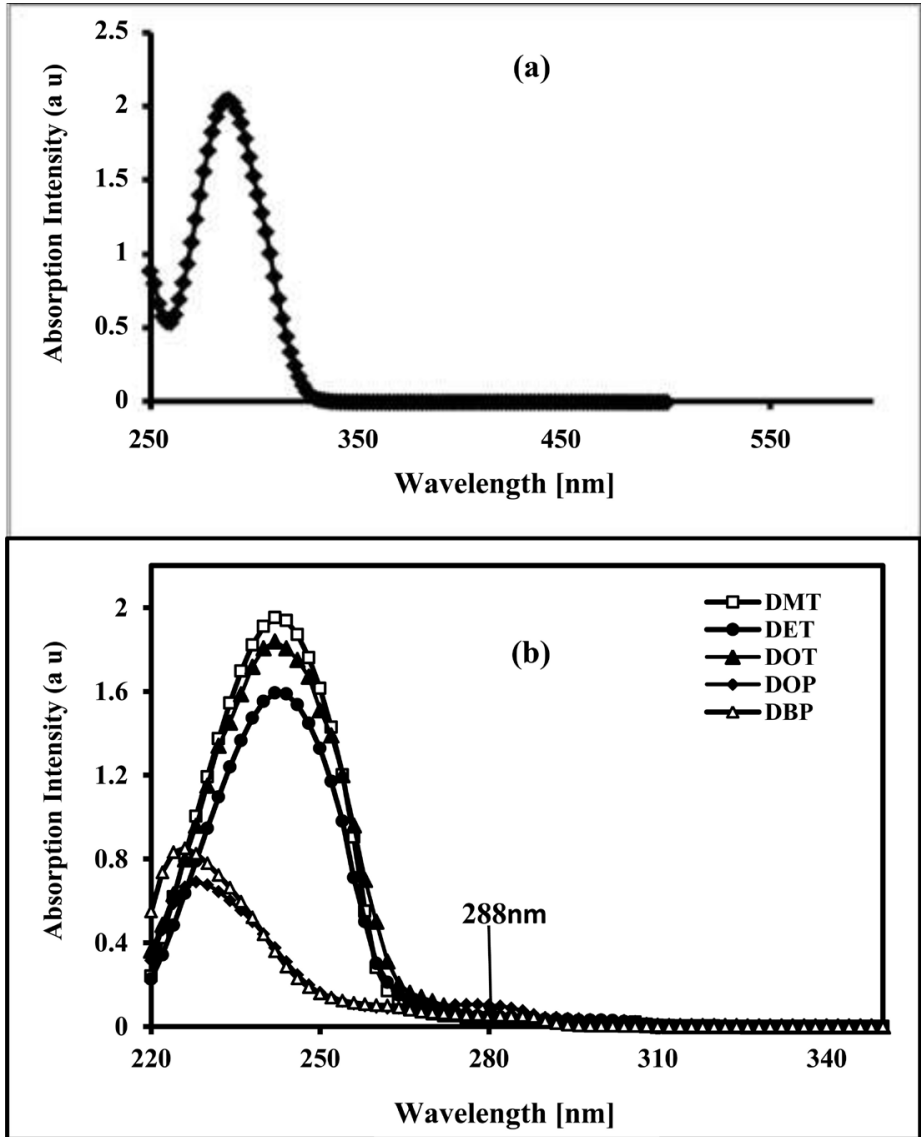

Figure 1. UV-absorption spectra of; (a) non-irradiated Poly (4-vinyl biphenyl) in DCE solution and (b) for Dimethyl terephthalate (DMT), Diethyl terephthalate (DET), Dioctyl terephthalate (DOT), Dioctyl phthalate (DOP), and Dibutyl phthalate (DBP).

\subsection{Effect of UV-Irradiation Time on Intensity of Fluorescence Spectra of Pure and Blended PVBP Films with DMT, DET, DOT, DBP and DOP Plasticizers}

A number of studies on the photodegradation of polystyrene and para-substituted polystyrene have received a considerable attention, mainly due to their industrial importance [18] [20]. However, the photodegradation of some substituted polystyrene has been studied extensively but no works have been reported on the photodegradation of puce and plasticized PVBP by fluorescence and FT-IR spectroscopic techniques.

The fluorescence spectrum of PVBP film composes from a minor band as monomer fluorescence at $\left(\lambda_{\max }=342 \mathrm{~nm}\right)$ and a major band at longer wavelength as excimer fluorescence at $\left(\left(\lambda_{\max }=372 \mathrm{~nm}\right)\right.$. The fluorescence spectrum of pure PVBP films irradiated at $\left(\lambda_{\text {ext }}=288 \mathrm{~nm}\right)$ is shown in Figure 2.

Blending of PVBP films with phthalates (DBP and DOP), and terephthalates (DMT, DET and DOT) plasticizers at $(5.0 \%, 10 \%$ and $15.0 \% \mathrm{wt}$.$) , showed a gra-$ dual decrease in the intensity of polymer fluorescence with increasing of amount of added plasticizer and decreases with increasing of irradiation times. The fluorescence spectra of blended PVBP films with (5\% wt, 10\% wt and 15\% wt) DOT 
is shown in Figure 3.

The fluorescence spectra of blended PVBP films with, (5\% wt, 10\% wt and $15 \% \mathrm{wt})$ DOP are shown in Figure 4.

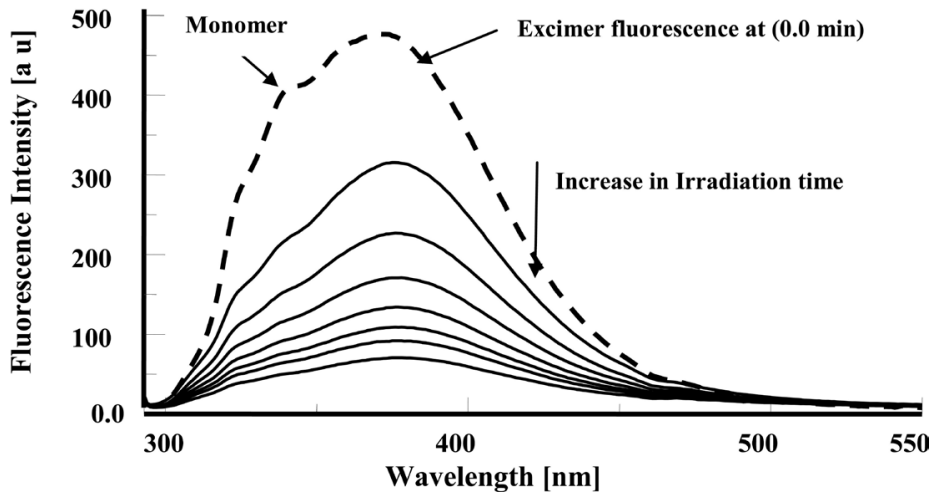

Figure 2. Fluorescence spectra of irradiated pure PVBP in solid film, at the exposure times $(0.0,15,30,45,60,75,90,120 \mathrm{~min})$, at $\left(\lambda_{\text {ext }}=288 \mathrm{~nm}\right)$.
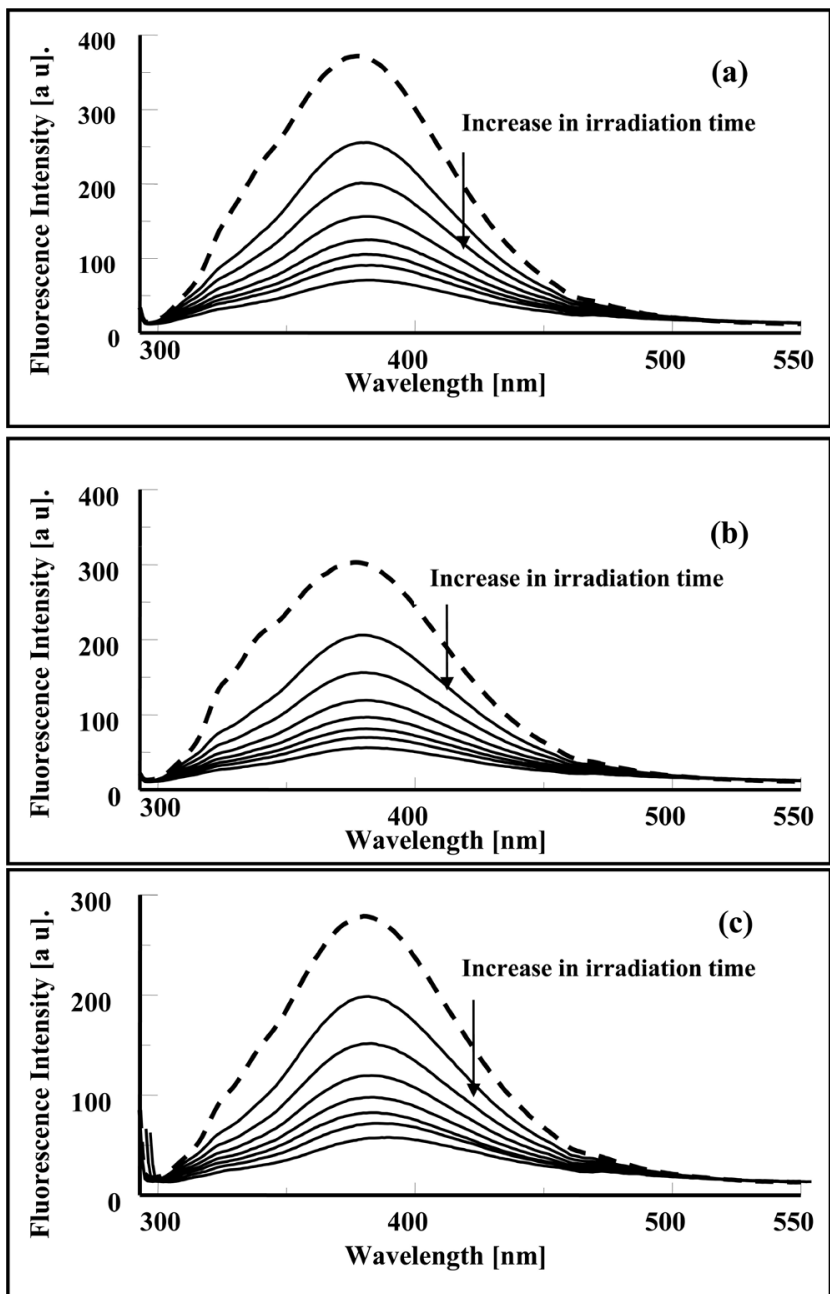

Figure 3. Fluorescence spectra of irradiated PVBP Blended with; (a) 5\% wt DOT, (b) $10 \%$ wt DOT and (c) $15 \%$ wt DOT in solid film, at exposure times $(0.0,15,30,45,60,75,90$, $120 \mathrm{~min})$, at $\left(\lambda_{\text {ext }}=288 \mathrm{~nm}\right)$. Dotted lines are for $0.0 \mathrm{~min}$ irradiation. 
As can be seen from Figure 3 and Figure 4, the fluorescence spectra for blended PVBP films, photo-irradiated for $(0.0$ - $120 \mathrm{~min})$ was obtained at room temperature and excitation wavelength of $288 \mathrm{~nm}$. Irradiation of the PVBP film at different exposure time was accompanied by the gradual quenching in the intensity of the excimer band, as well as a small red shift in the $\left(\lambda_{\max }\right)$ of the excimer fluorescence band of (372 - $380 \mathrm{~nm})$, as shown in Table 1.
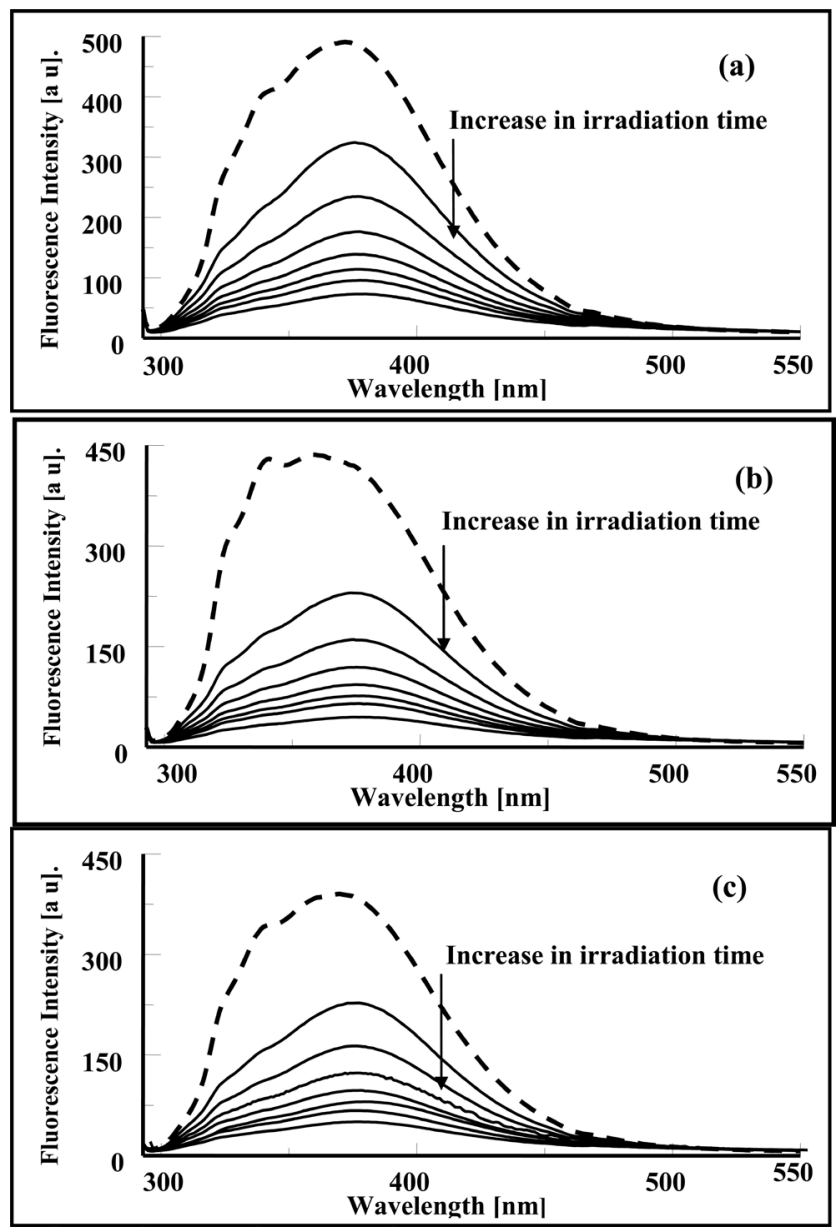

Figure 4. Fluorescence spectra of irradiated PVBP Blended with; (a) 5\% wt DOP, (b) 10\% wt DOP and (c)15\% wt DOP in solid film, at exposure times $(0.0,15,30,45,60,75,90$, $120 \mathrm{~min})$, at $\left(\lambda_{\mathrm{ext}}=288 \mathrm{~nm}\right)$. Dotted lines are for $0.0 \mathrm{~min}$ irradiation.

Table 1. Red shift in the $\left(\lambda_{\max }\right)$ of the excimer fluorescence band of irradiated plasticized PVBP films.

\begin{tabular}{ccccc}
\hline Added Plasticizer & $\begin{array}{c}\text { PVBP }+0.0 \% \\
\text { Plasticizer }\end{array}$ & $\begin{array}{c}\text { PVBP + 5\% } \\
\text { Plasticizer }\end{array}$ & $\begin{array}{c}\text { PVBP + 10\% } \\
\text { Plasticizer }\end{array}$ & $\begin{array}{c}\text { PVBP + 15\% } \\
\text { Plasticizer }\end{array}$ \\
\hline DMT & 372 & 377 & 378 & 380 \\
DET & 372 & 373 & 376 & 377 \\
DOT & 372 & 375 & 377 & 377 \\
DBP & 372 & 374 & 375 & 376 \\
DOP & 372 & 374 & 376 & 378 \\
\hline
\end{tabular}


It is more likely that this red shift occurs as result of photodegradation of the polymeric chains, and can be attributed to the formation of conjugated double bonds along the polymer chain during the photodegradation by hydrogen abstraction process [36] [42]. The shift in the excimer fluorescence band is in good agreement with that reported with irradiated blended polystyrene [8], poly (4-methoxystyrene) [30] and poly (4-methylstyrene) [32]. Tovborg and Kops [36] pointed out that quenching of polymeric emission might be attributed to the energy transportation of the oxides formed by the photo-oxidation of polymeric chromophores, or to the quenching effect of the peroxide formed during UV-irradiation.

Blending of PVBP solid films with different percentages of DMT, DET, DOT, DBP and DOP plasticizers, showed only decrease in the intensity of the fluorescence bands without formation of exciplex fluorescence at longer wavelength. Most likely, the energy transfer complex formed between the polymer chromophore and the plasticizer molecule is not stable enough to give exciplex fluorescence emission [41]. The decrease in excimer fluorescence may be attributed to; first, quenching of excited polymer chromophores by plasticizer molecules [41]; second, to the distraction of polymeric chains by photochemical reaction through formation of free radical reactions [5] [7].

\subsection{Kinetics and Mechanism of Photodegradation of Pure and Blended PVBP Solid Films}

From the quenching process for the intensity of excimer fluorescence of irradiated PVBP films for different intervals of time and by blending with phthalate and terephthalate plasticizers, some kinetic parameters can be collected by applying Al Ani and Hawi relationship [30]. The intensity of excimer fluorescence of non irradiated polymer film is denoted by $\left(I_{E X}^{o}\right)$, whereas $\left(I_{E X}\right)$ represents the fluorescence intensity of irradiated pure and blended PVBP films at different intervals of time. The quenching ratio is denoted by $\left[\left(I_{E X}^{o}\right) /\left(I_{E X}\right)\right]$, and can be represented by the following relationship [30]:

$$
\left(\frac{I_{E X}^{o}}{I_{E X}}\right)^{*}=1+\left[\left\{\left(k_{P Q}^{\prime}\right)(A)\right\}(t)\right]
$$

where $[A]=$ number of (photons/s) absorbed by polymeric chromophores.

$t=$ time of irradiation in $\mathrm{s}$.

$k_{P Q}^{\prime}=$ rate constant.

In the photo-quenching processes, if we assume that the number of photons released from the light source and absorbed by polymer chromophores is constant $(A)$, Then according to (Equation (1)), we can write:

$$
k_{P Q}=\left\{\left(k_{P Q}^{\prime}\right)(A)\right\}
$$

where $\left(k_{P Q}\right)$ is the photo-quenching rate constant, and the efficiency of quenching ratio $\left[I_{[E X]^{*}}^{o} / I_{[E X]^{*}}\right]$ is given by the following equation: 


$$
\left(\frac{I_{E X}^{o}}{I_{E X}}\right)^{*}=1+\left[\left(k_{P Q}\right)(t)\right]
$$

According to Equation (2), $\left[I_{[E X]^{*}}^{o} / I_{[E X]^{*}}\right]$-values were plotted against time of irradiations $(t)$. From the plots, the photo-quenching rate constant $\left(k_{P Q}\right)$ values and quenching efficiency ratio $\left[I_{[E X]^{*}}^{o} / I_{[E X]^{*}}\right]$ were calculated and used to estimate the efficiency of photodegradation processes for pure and blended irradiated polymer. The plots of the ratio of excimer fluorescence $\left[I_{[E X]^{*}}^{o} / I_{[E X]^{*}}\right]$ against the different irradiation times of pure and blended PS films with $0.0 \%$ wt, $5.0 \%$ wt, $10.0 \%$ wt and $15.0 \%$ wt of DMT, DET and DOT plasticizers are presented in Figure 5.
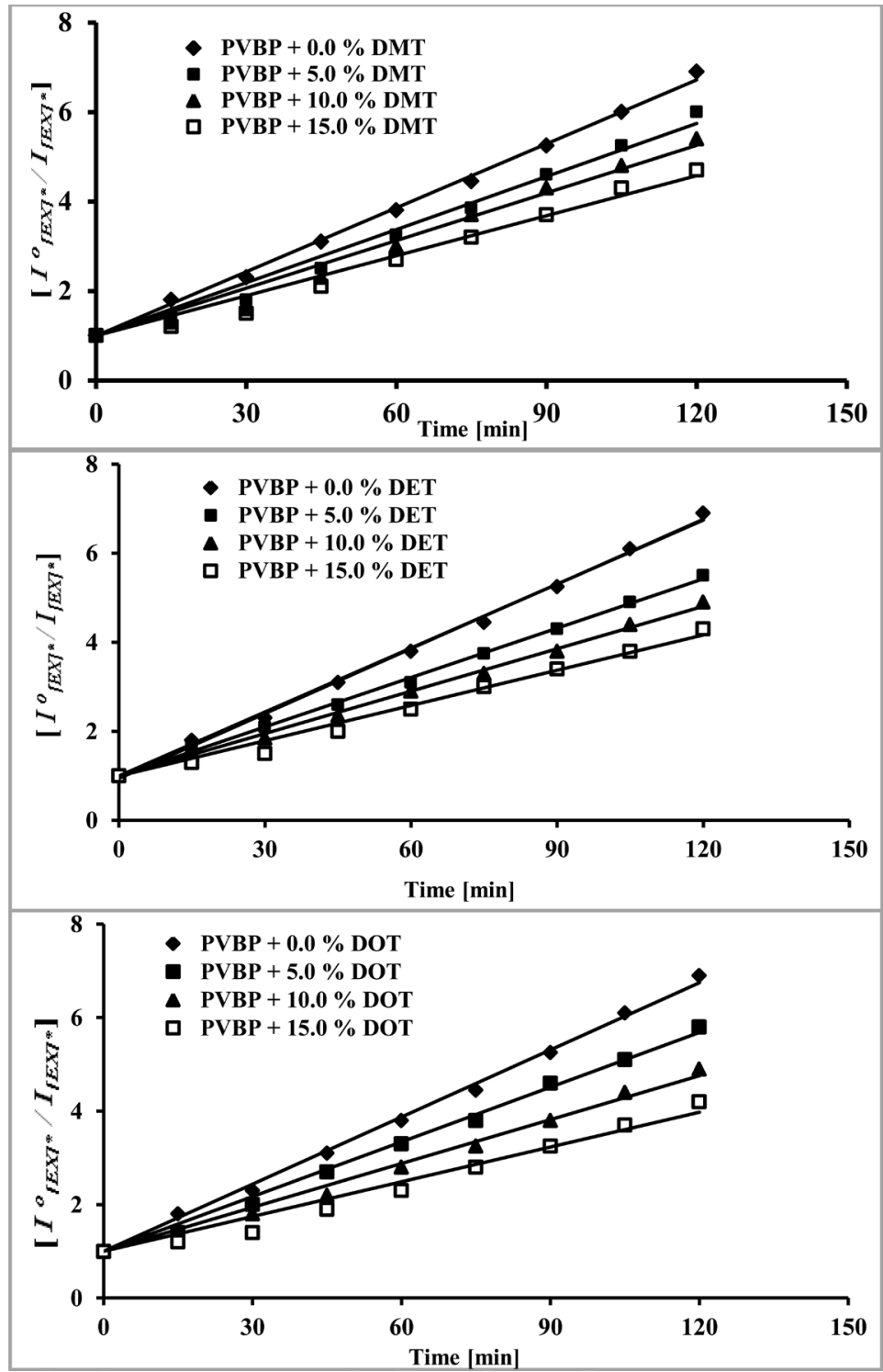

Figure 5. Effect of added mass percent of DMT, DET and DOT on excimer fluorescence quenching of blended PVBP films at different irradiation times. 
As can be noticed from Figure 5, an increase in the amount of added terephthalate plasticizers resulted in the decrease in the degradation ratio of $\left[I_{[E X]^{*}}^{o} / I_{[E X]^{*}}\right]$ with the increase of exposure time, and decrease in the photoquenching rate constant. On the other hand, the increase in the amount of added phthalate plasticizers resulted in a higher decease in the photo-quenching rate constant $\left(k_{P Q}\right)$ as shown in Figure 6. The same results were obtained in the photodegradation of blended Poly (4-tert-butylstyrene) and Poly (4-methylstyrene) films [10] [32]. Blending with DBP showed a higher photo quenching rate constant than in blending with other phthalate or terephthalate plasticizers.

As can be seen from Figure 4 and Figure 5, the photo-quenching efficiencies of excimer fluorescence $\left(I_{[E X]^{*}}^{o} / I_{[E X]^{*}}\right)$ of pure and blended P4VBP were plotted at different intervals of exposure time and at different amount of added plasticizers and found to increase by the increase in exposure times, and to decrease by the increase in the amount of blended plasticizers.

From Figure 5 and Figure 6, the photo quenching rate constants in blending with phthalate plasticizers are higher than that obtained in blending with terephthalates plasticizers. The order of increase in photo quenching by blending with terephthalates plasticizers is DOT, DET and DMT, whereas in blending with phthalate plasticizers, DOP showed a higher efficiency of photo-quenching

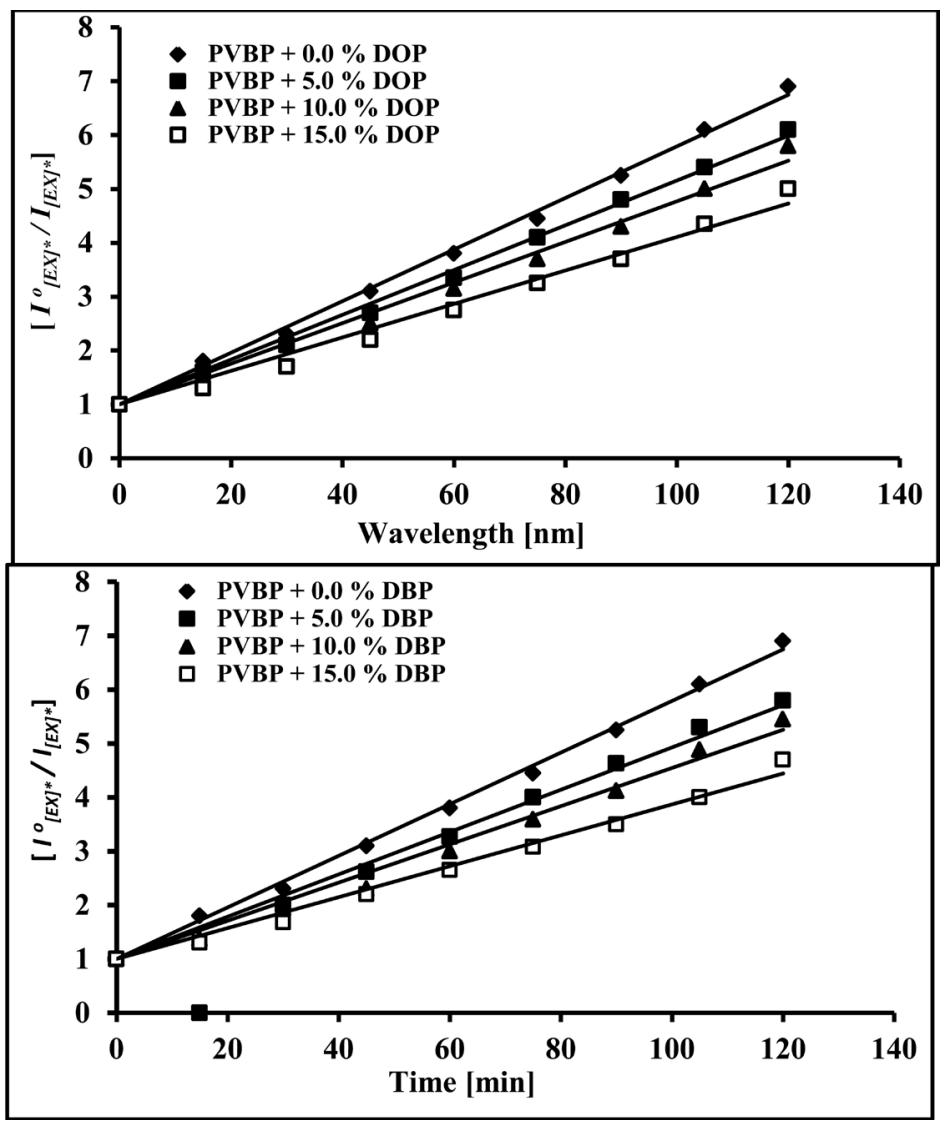

Figure 6. Effect of added mass percent of DBP and DOP on excimer fluorescence quenching of blended PVBP films at different irradiation times. 
of polymeric fluorescence.

The increase in irradiation times to PVBP films caused an increase to both the excimer fluorescence ratio and to the photo-quenching rate constant (kPQ), this indicates that fluorescence quenching by added plasticizers may be accompanied by photochemical reaction in the polymer backbone. Also, there is a possible reaction, between the free radicals formed by the chain scission of polymeric chains and the added plasticizer molecules, which increase the efficiency of the quenching process. It was reported that chains scissions and changes in the molecular weight distribution, as well as, photo-oxidation process that was interpreted as a reaction involving benzene ring-opening photo-oxidation was also the process that resulted from irradiation of polystyrene and substituted polystyrene in the presence of polymeric additives [35] [37]. It has been reported that the photo stability of PS was reduced by the addition of polymeric additives, which depends on the chemical structure of the additive. Chain scissions, and changes in the molecular weight distribution, were the main reactions resulted from the photo-oxidation of irradiated plasticized polystyrene films [3].

From the data in Figure 5 and Figure 6, and by applying the Al Ani-Hawi relationship [30], where the ratio $\left(I_{[E X]^{*}}^{o} / I_{[E X]^{*}}\right)$ was plotted against different intervals of the exposure time, from the slope of the obtained lines, $(k P Q)$ values were calculated for pure and blended PVBP films with different percentages of DMT, DET, DOT, DBP and DOP, and are presented in Table 2.

Table 2. Relative intensities of the ratio $\left(I_{E X}^{o} / I_{E X}\right)$ for excimer fluorescence and excimer fluorescence photo- quenching rate constant values $\left(k_{P Q}\right)$ of irradiated pure and blended PVBP films.

\begin{tabular}{|c|c|c|c|c|c|c|c|}
\hline Polymer & $\mathrm{E}_{\text {xcimer }}(\mathrm{nm})(\mathrm{Max})$ & Plasticizers (\%) & Plasticizers (\%) & Time (min.) & $\left(I_{E X}^{o} / I_{E X}\right)$ Ratio & $\mathrm{R}^{2}$ & $k_{P Q}$ \\
\hline PVBP & 372 & $0.0 \%$ & $0.0 \%$ & 120 & 6.902 & 0.9978 & 0.0479 \\
\hline PVBP & 373 & $5 \%-\mathrm{DMT}$ & $5 \%-\mathrm{DMT}$ & 120 & 6.152 & 0.9855 & 0.0394 \\
\hline PVBP & 376 & $10 \%-\mathrm{DMT}$ & $10 \%-\mathrm{DMT}$ & 120 & 5.433 & 0.9799 & 0.0355 \\
\hline PVBP & 379 & $15 \%$ - DMT & $15 \%-\mathrm{DMT}$ & 120 & 4.739 & 0.9777 & 0.0289 \\
\hline PVBP & 377 & $5 \%-\mathrm{DET}$ & $5 \%-\mathrm{DET}$ & 120 & 5.937 & 0.9980 & 0.0388 \\
\hline PVBP & 378 & $10 \%-\mathrm{DET}$ & $10 \%-\mathrm{DET}$ & 120 & 4.987 & 0.9972 & 0.0317 \\
\hline PVBP & 383 & $15 \%-\mathrm{DET}$ & $15 \%-\mathrm{DET}$ & 120 & 4.367 & 0.9857 & 0.0264 \\
\hline PVBP & 375 & $5 \%-\mathrm{DOT}$ & $5 \%-\mathrm{DOT}$ & 120 & 5.552 & 0.9951 & 0.0390 \\
\hline PVBP & 377 & $10 \%-\mathrm{DOT}$ & $10 \%-\mathrm{DOT}$ & 120 & 4.908 & 0.9906 & 0.0313 \\
\hline PVBP & 378 & $15 \%-\mathrm{DOT}$ & $15 \%-\mathrm{DOT}$ & 120 & 4.064 & 0.9720 & 0.0248 \\
\hline PVBP & 371 & $5 \%-\mathrm{DBP}$ & $5 \%-\mathrm{DBP}$ & 120 & 5.811 & 0.9770 & 0.0395 \\
\hline PVBP & 360 & $10 \%-\mathrm{DBP}$ & $10 \%-\mathrm{DBP}$ & 120 & 5.445 & 0.9951 & 0.0355 \\
\hline PVBP & 358 & $15 \%-\mathrm{DBP}$ & $15 \%-\mathrm{DBP}$ & 120 & 4.652 & 0.9907 & 0.0294 \\
\hline PVBP & 373 & $5 \%$ - DOP & $5 \%$ - DOP & 120 & 6.906 & 0.9973 & 0.0429 \\
\hline PVBP & 374 & $10 \%-\mathrm{DOP}$ & $10 \%-\mathrm{DOP}$ & 120 & 5.987 & 0.9891 & 0.0378 \\
\hline PVBP & 378 & $15 \%-\mathrm{DOP}$ & $15 \%-\mathrm{DOP}$ & 120 & 5.079 & 0.9989 & 0.0311 \\
\hline
\end{tabular}


As can be seen from Table 2, blending PVBP films with phthalate and terephthalate plasticizers, gave a lower values for the photo-quenching rate constant in comparison with that for pure polymer. It was found that the parasubstituted group in the phenyl ring of the monomer and the structure and bulkiness of the used plasticizer molecule play a big role in the photo-quenching and photo-stability of plasticized polymers [9] [10]. Furthermore, the photostability of polymer chains was found to depend on the above mentioned factors as well as the UV-exposure time. It has been reported previously that the presence of plasticizer molecules in polymer matrix caused lowering in the activation energy during the photodegradation of poly (fluorostyrene) isomers films [23] [24], and was attributed to the lowering in the charge transfer character of the excimer conformation. It was also found that the main process resulted from irradiation of blended polymer film in presence of air, were photo-oxidation of polymeric chromophores as well as chain scission and crosslinking processes [33] [34].

The photo-quenching rate constant (kPQ) of excimer fluorescence increases with the increase in molar mass of the used phthalate and terephthalate plasticizers; a fact that correlates well with that obtained for the thermal degradation of substituted polystyrenes [1] [4]. The plot of the increase in the change of efficiency of excimer fluorescence quenching $\left(\Delta \mathrm{k}_{\mathrm{PQ}}\right)$ with the increase in molar mass is shown in Figure 7.

As can be observed from Figure 7, phthalate plasticizers showed a higher efficiency of photodegradation in comparison with that obtained for the photodegradation in blending the polymer with terephthalate plasticizers. The photodegradation process was found to increase by the presence of air during polymer irradiation process. It depends upon the rate of oxygen diffusion into the polymer matrix, and to the stability of the formed energy transfer complex between oxygen molecules and polymer structures [42] [43] [44] [45].

Furthermore, it is more likely that the increase in the bulkiness of plasticizer molecule caused enhancement to the degradation process through the decrease

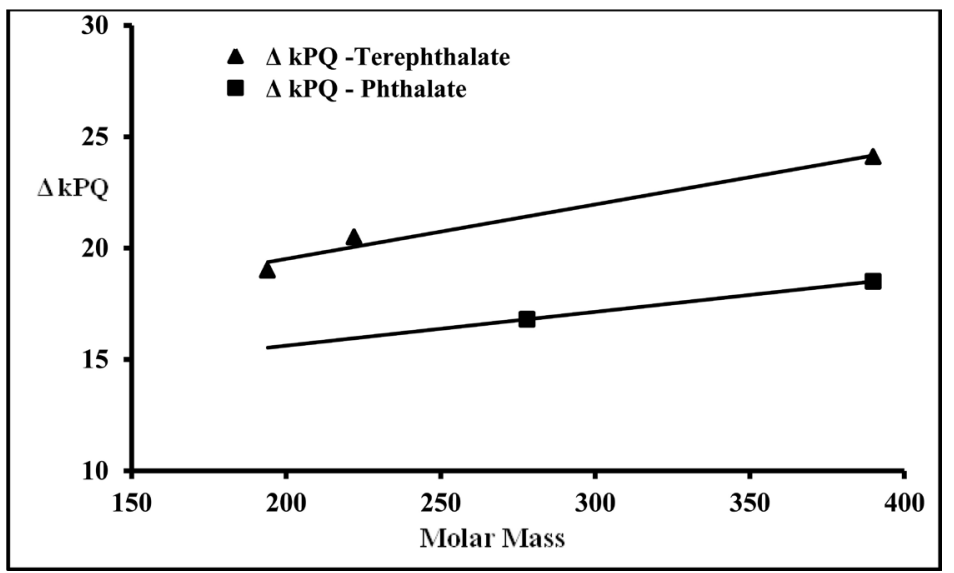

Figure 7. Effect of molar mass of the added plasticizer on the change in the photoquenching rate constant $\left(\Delta \mathrm{k}_{\mathrm{PQ}} \times 10^{-3}\right)$ of PVBP irradiated films. 


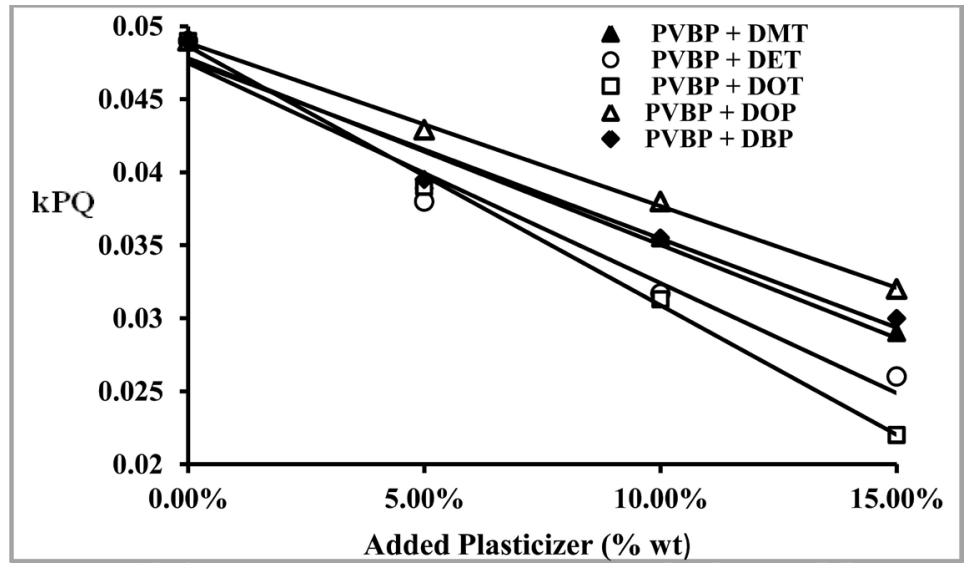

Figure 8. Effect of amount of added plasticizer on the change in the photo-quenching rate constant $\left(\mathrm{kPQ} \times 10^{-3}\right)$ of PVBP irradiated films.

in the stability of the energy transfer complex between excited polymer chromophores and the ground state plasticizer molecules [46]. It was reported that the photodegradation process is dependent upon the chemical structure of the substituent and also on the position of substitution in phenyl ring of the styrene chromophores [42] [43].

The effect of the increase of percentage of added plasticizers to the photodegradation process and to the photo-quenching rate constant is shown in Figure 8.

As can be seen from Figure 8, the increase in amount of added plasticizer caused a decrease the photo-quenching rate constant of irradiated polymer chains and found to depend upon the structure of the used plasticizers, and also on the amount of added plasticizers.

From the data obtained for irradiated pure and blended PVBP solid films, we can notice that the photostability of PVBP is similar to that of polystyrene. This fact can be explained as phenyl ring substitution (as an inert group) in the para position of the styrene monomer increases the photostability of PVBP polymer towards irradiation. On the other hand, the phenyl substitutions make the hydrogen abstracting process during the irradiation process as a difficult process.

\subsection{FT-IR Spectra for Non-Irradiated and Irradiated Pure and Blended PVBP Solid Films}

In order to confirm the presence of photo degradation in the irradiated pure and blended PVBP films with different amount of doped phthalate and terephthalate plasticizers, $F T-I R$ spectra were recorded of non-irradiated and irradiated films under atmospheric oxygen, and at $298 \mathrm{~K}$.

Figure 9 shows the $F T-I R$ spectra of non-irradiated and irradiated for $(0.0$ and $120 \mathrm{~min}$ ) of pure PVBP solid film, and were recorded immediately before and after irradiation.

As can be seen from Figure 9, chemical changes were assessed by FT-IR spectra for photo-irradiated pure solid film. These changes of decrease in absorbance for some bands, increase in other bands and red shift in the absorption of 


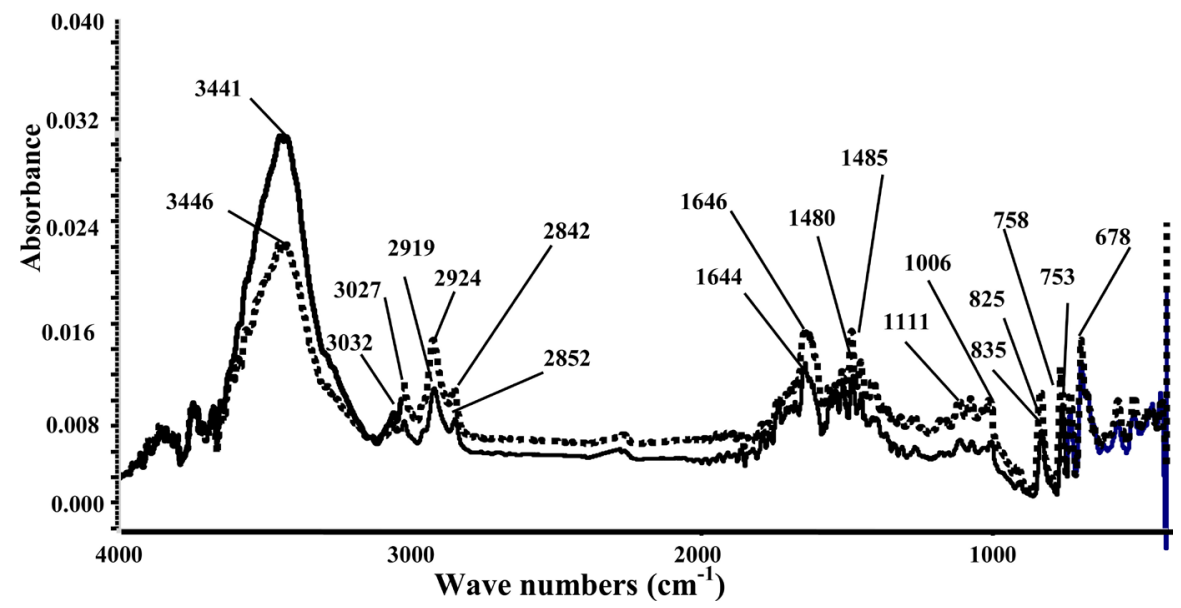

Figure 9. FT-IR spectra of non-irradiated film (solid line) and irradiated film for $120 \mathrm{~min}$ (dotted line), in solid films of PVBP, at $\left(\lambda_{\text {ext }}=288 \mathrm{~nm}\right)$.

Table 3. FT- $I R$ band position in pure PVBP irradiated for, $(0.00 \mathrm{~min}$ and $120 \mathrm{~min})$ at $\left(\lambda_{\text {ext }}=\right.$ $288 \mathrm{~nm})$.

\begin{tabular}{|c|c|c|c|c|c|}
\hline Polymer & $\begin{array}{l}\text { Band } \\
\left(\mathrm{cm}^{-1}\right)\end{array}$ & $\begin{array}{l}\text { Band }\left(\mathrm{cm}^{-1}\right) \\
(0.0 \mathrm{~min})\end{array}$ & $\begin{array}{c}\text { Band }\left(\mathrm{cm}^{-1}\right) \\
(120 \mathrm{~min})\end{array}$ & Type of vibration & Intensity \\
\hline \multirow{9}{*}{ PVBP } & 3446 & 3446 & 3441 & $(\mathrm{OH})$, stretching vibration of carboxylic acid & Decreasing \\
\hline & 3027 & 3027 & 3032 & $(=\mathrm{C}-\mathrm{H})$, stretching vibration of Aromatic & Increasing \\
\hline & 2919 & 2919 & 2924 & $(\mathrm{C}-\mathrm{H})$, stretching vibration of benzene & Increasing \\
\hline & 2842 & 2842 & 2852 & $(\mathrm{O}-\mathrm{H}\}$ stanching vibration & Increasing \\
\hline & 1644 & 1644 & 1646 & $(\mathrm{C}=\mathrm{C}\}$ stanching vibration in dines & Increasing \\
\hline & 1480 & 1480 & 1485 & $(\mathrm{C}=\mathrm{C})$ stretching of aromatic & Increasing \\
\hline & 1111 & 1111 & 1116 & (C-O) stanching vibration & Decreasing \\
\hline & 825 & 825 & 835 & Conjugated double bond & Increasing \\
\hline & 753 & 753 & 758 & & Decreasing \\
\hline
\end{tabular}

many bands, are corresponding to the photo-oxidation and photodegradation of PVBP polymeric chains. It was noted that the most demonstrated trend is the increase of the absorbance bands that were resulting from polymer chains photodegradation, are shown in Table 3.

As can be seen from Figure 9 and Table 3, modifications occur in the intensity of different absorption bands in the $F T-I R$ spectra of the irradiated pure and blended PVBP films. These changes correspond to photo-oxidation and photodegradation of polymeric chains [47] [48]. Transformation is clearly demonstrated by the decrease in absorbance of band at $\left(3800-3400 \mathrm{~cm}^{-1}\right)$, and by the increase in the absorption band at $3027 \mathrm{~cm}^{-1}, 2919 \mathrm{~cm}^{-1}, 2842 \mathrm{~cm}^{-1}, 1644 \mathrm{~cm}^{-1}$, $1480 \mathrm{~cm}^{-1}, 1111 \mathrm{~cm}^{-1}, 825 \mathrm{~cm}^{-1}$ and $753 \mathrm{~cm}^{-1}$, resulting from the polymer chains photodegradation. Rabek and Ranby have assigned the absorption band at 3440 $\mathrm{cm}^{-1}$ to the increase in the photo-oxidation of benzene rings and to the decrease in aromacity in the polymer sample [3]. They have reported during irradiation 
of polystyrene films, three cases of oxidation of the benzene ring being observed. The formation of benzyl acetophenone chromophores; acetophenone structures; and conjugated double bonds, were the main products resulted from the photooxidation of polystyrene films. The same observations were observed in the UV-irradiation of Substituted polystyrene in solid films [19] [44].

Figure 9 shows the $F T-I R$ spectra of non-irradiated and irradiated for $(0.0$ and $120 \mathrm{~min}$ ) of blended PVBP with (10\% DOT), (10\% DET) and (10\% DMT) in solid films at irradiation wavelength of $288 \mathrm{~nm}$.

As can be seen from Figure 10 and Figure 11, irradiation of PVBP blended films in the presence of air with (10\% added plasticizers), caused photodegradation
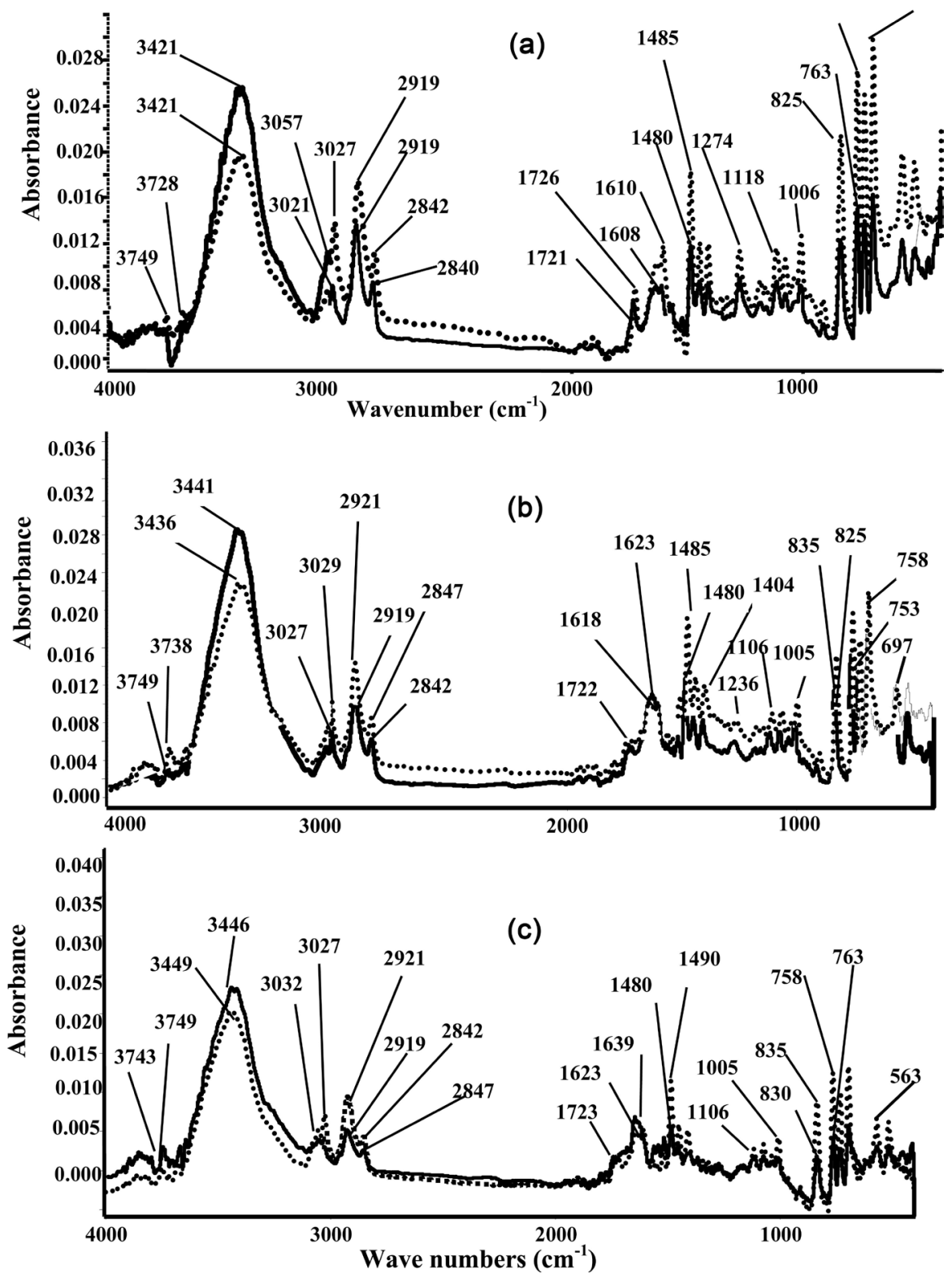

Figure 10. FT-IR spectra of non-irradiated solid film (solid line) and irradiated solid film for 120 min (dotted line), of PVBP blended with; (a) with DOT, (b) with DET and (c) with DMT plasticizers. 

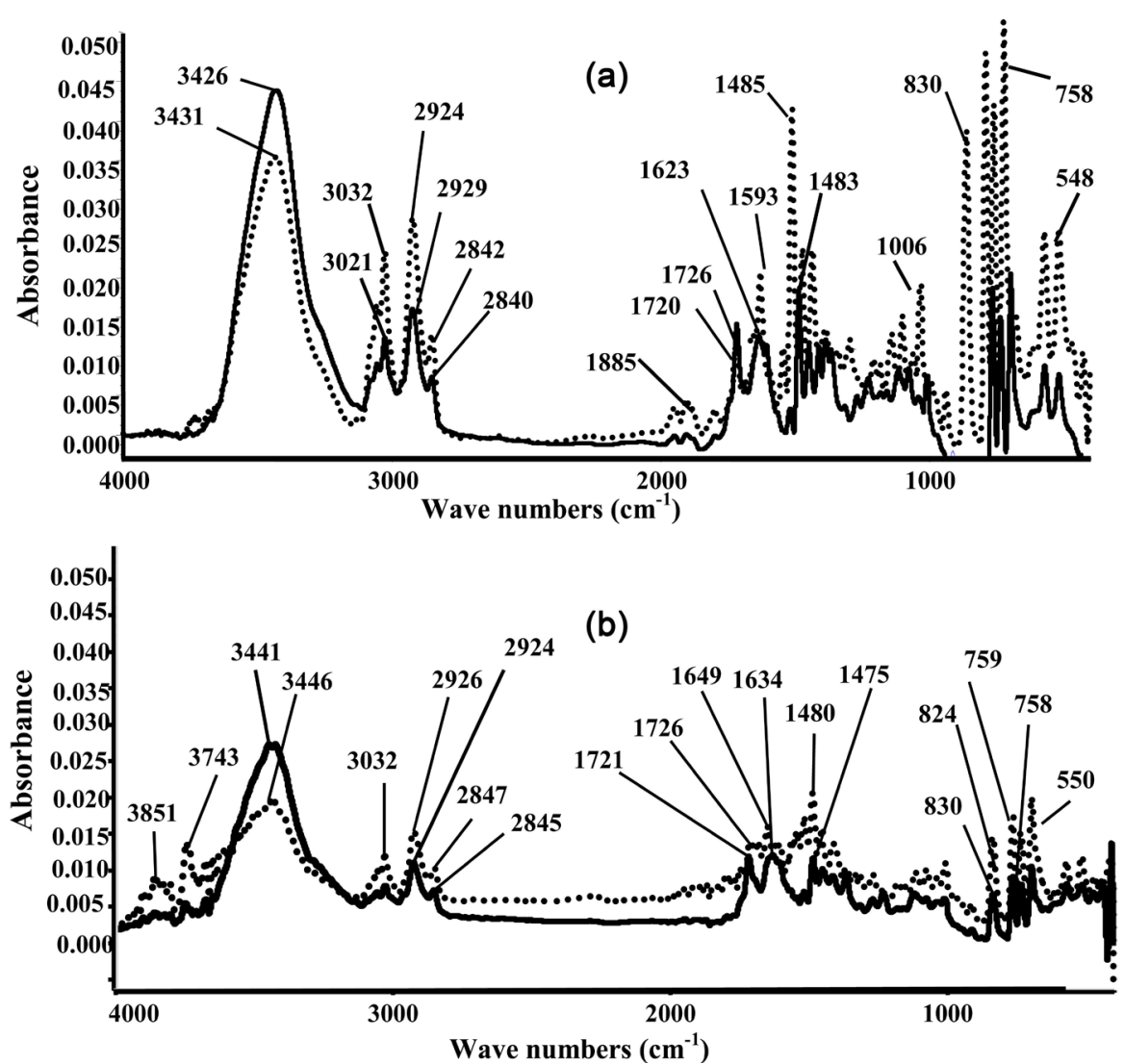

Figure 11. FT-IR spectra of non-irradiated solid film (solid line) and irradiated solid film for 120 min (dotted line), of PVBP blended with; (a) with DOP, and (b) with DBP plasticizers.

and photo-oxidation of polymeric chains leading to the increase the absorption intensity in many regions in the spectrum. Chemical changes were assessed by $F T-I R$ spectra for irradiated blended PVBP solid films, and show typical functional group, in the hydroxyl $\left(3800-3000 \mathrm{~cm}^{-1}\right)$; C-H stretching vibration in the aliphatic chain and in aromatic rings $\left(2800-3100 \mathrm{~cm}^{-1}\right)$; carboxyl stretching vibration $\left(1800-1600 \mathrm{~cm}^{-1}\right)$; and deformation vibration $\left(1400-600 \mathrm{~cm}^{-1}\right)$ regions.

The increase in the intensity, decrease in the intensity and red shift in position of FT-IR absorption bands for pure and blended PVBP with (10.0\% wt.) DOT, DET and DMT are summarized in Table 4 and Table 5.

As can be seen from Table 5, the increase in intensity of the absorption bands and the small red shift in these bands upon blending with these plasticizer can give good indication that there is a change in the photo-product resulted from irradiations.

As can be seen in Figure 10 and Figure 11, the photo-oxidation of polymeric chains of pure and blended PVBP films, leads to increase in the absorption intensity in the bands at $1716 \mathrm{~cm}^{-1}, 1649 \mathrm{~cm}^{-1}, 1480 \mathrm{~cm}^{-1}$ and $1404 \mathrm{~cm}^{-1}$. The bands found at $1649 \mathrm{~cm}^{-1}$ and $1480 \mathrm{~cm}^{-1}$, can be ascribed to stretching vibration of the substituted benzene rings; it means that the aromatic rings lose their symmetry through the photo-oxidation processes, and are almost in the same 
Table 4. FT-IR band position in blended PVBP with (10.0\% wt) DOT, DET and DMT irradiated for, $(0.00 \mathrm{~min}$ and $120 \mathrm{~min})$ at $\left(\lambda_{\text {ext }}=288 \mathrm{~nm}\right)$.

\begin{tabular}{|c|c|c|c|c|c|}
\hline Polymer & Band $\left(\mathrm{cm}^{-1}\right)$ & Band $\left(\mathrm{cm}^{-1}\right)(0.0 \mathrm{~min})$ & Band $\left(\mathrm{cm}^{-1}\right)(120 \mathrm{~min})$ & Type of vibration & Intensity \\
\hline \multirow{12}{*}{$\mathrm{PVBP}+10.0 \% \mathrm{DOT}$} & 3749 & 3749 & 3748 & $\mathrm{C}-\mathrm{O}-\mathrm{C}$ stretching vibration & Increasing \\
\hline & 3421 & 3421 & 3421 & $(\mathrm{O}-\mathrm{H})$, stretching vibration of carboxylic acid & Decreasing \\
\hline & 3021 & 3021 & 3032 & $(=\mathrm{C}-\mathrm{H})$, stretching vibration of Aromatic & Increasing \\
\hline & 2919 & 2919 & 2919 & $(\mathrm{C}-\mathrm{H})$, stretching vibration of benzene & Increasing \\
\hline & 2840 & 2840 & 2842 & $(\mathrm{O}-\mathrm{H})$ stanching vibration & Increasing \\
\hline & 1721 & 1721 & 1726 & $(\mathrm{C}=\mathrm{O})$ stanching vibration & Increasing \\
\hline & 1608 & 1608 & 1610 & $(\mathrm{C}=\mathrm{C})$ stanching vibration in dines & Increasing \\
\hline & 1480 & 1480 & 1485 & $(\mathrm{C}=\mathrm{C})$ stretching of aromatic & Increasing \\
\hline & 1116 & 1116 & 1118 & $(\mathrm{C}-\mathrm{O})$ stanching vibration & Decreasing \\
\hline & 1106 & 1106 & 1106 & & Increasing \\
\hline & 825 & 825 & 835 & Conjugated double bond & Increasing \\
\hline & 763 & 763 & 768 & $(=\mathrm{C}-\mathrm{H})$ stretch vibration & Decreasing \\
\hline \multirow{12}{*}{$\mathrm{PVBP}+10.0 \% \mathrm{DET}$} & 3743 & 3743 & 3749 & $\mathrm{C}-\mathrm{O}-\mathrm{C}$ stretching vibration & Increasing \\
\hline & 3446 & 3446 & 3449 & $(\mathrm{OH})$, stretching vibration of carboxylic acid & Decreasing \\
\hline & 3021 & 3021 & 3032 & $(=\mathrm{C}-\mathrm{H})$, stretching vibration of Aromatic & Increasing \\
\hline & 2919 & 2919 & 2921 & $(\mathrm{C}-\mathrm{H})$, stretching vibration of benzene & Increasing \\
\hline & 2842 & 2842 & 2847 & $(\mathrm{O}-\mathrm{H})$ stanching vibration & Increasing \\
\hline & 1721 & 1721 & 1722 & $(\mathrm{C}=\mathrm{O})$ stanching vibration & \\
\hline & 1618 & 1618 & 1623 & $(\mathrm{O}-\mathrm{H})$ stanching vibration & Increasing \\
\hline & 1480 & 1480 & 1485 & $(\mathrm{C}=\mathrm{C})$ stanching vibration in dines & Increasing \\
\hline & 1234 & 1234 & 1236 & $(\mathrm{C}=\mathrm{C})$ stretching of aromatic & Increasing \\
\hline & 1111 & 1111 & 1116 & $(\mathrm{C}-\mathrm{O})$ stanching vibration & Decreasing \\
\hline & 825 & 825 & 835 & Conjugated double bond & Increasing \\
\hline & 753 & 753 & 758 & $=\mathrm{C}-\mathrm{H}$ stretch vibration & Decreasing \\
\hline \multirow{11}{*}{$\mathrm{PVBP}+10.0 \% \mathrm{DMT}$} & 3743 & 3743 & 3749 & $\mathrm{C}-\mathrm{O}-\mathrm{C}$ stretching vibration & Increasing \\
\hline & 3446 & 3446 & 3447 & $(\mathrm{OH})$, stretching vibration of carboxylic acid & Decreasing \\
\hline & 3027 & 3027 & 3032 & $(=\mathrm{C}-\mathrm{H})$, stretching vibration of Aromatic & Increasing \\
\hline & 2919 & 2919 & 2921 & $(\mathrm{C}-\mathrm{H})$, stretching vibration of benzene & Increasing \\
\hline & 2842 & 2842 & 2847 & $(\mathrm{O}-\mathrm{H})$ stanching vibration & Increasing \\
\hline & 1721 & 1721 & 1723 & $(\mathrm{C}=\mathrm{O})$ stanching vibration & \\
\hline & 1623 & 1623 & 1639 & $(\mathrm{C}=\mathrm{C})$ stanching vibration in dines & Increasing \\
\hline & 1480 & 1480 & 1490 & $(\mathrm{C}=\mathrm{C})$ stretching of aromatic & Increasing \\
\hline & 1106 & 1106 & 1106 & $(\mathrm{C}-\mathrm{O})$ stanching vibration & Decreasing \\
\hline & 830 & 830 & 835 & Conjugated double bond & Increasing \\
\hline & 758 & 758 & 763 & $(=\mathrm{C}-\mathrm{H})$ stretch vibration & Decreasing \\
\hline
\end{tabular}


Table 5. FT-IR band position in blended PVBP with (10.0\% wt) DOP and (10.0\% wt) DBP irradiated for, $(0.00 \mathrm{~min}$ and $120 \mathrm{~min})$ at $\left(\lambda_{\text {ext }}=288 \mathrm{~nm}\right)$.

\begin{tabular}{|c|c|c|c|c|c|}
\hline Polymer & Band $\left(\mathrm{cm}^{-1}\right)$ & Band $\left(\mathrm{cm}^{-1}\right)(0.0 \mathrm{~min})$ & Band $\left(\mathrm{cm}^{-1}\right)(120 \mathrm{~min})$ & Type of vibration & Intensity \\
\hline \multirow{13}{*}{$\mathrm{PVBP}+10.0 \% \mathrm{DOT}$} & 3742 & --- & 3742 & $\mathrm{C}-\mathrm{O}-\mathrm{C}$ stretching vibration & New band \\
\hline & 3426 & 3426 & 3431 & $(\mathrm{O}-\mathrm{H})$, stretching vibration of carboxylic acid & Decreasing \\
\hline & 3021 & 3021 & 3032 & $(=\mathrm{C}-\mathrm{H})$, stretching vibration of Aromatic & Increasing \\
\hline & 2924 & 2924 & 2929 & $(\mathrm{C}-\mathrm{H})$, stretching vibration of benzene & Increasing \\
\hline & 2840 & 2840 & 2840 & $(\mathrm{O}-\mathrm{H})$ stanching vibration & Increasing \\
\hline & 1720 & 1720 & 1726 & $(\mathrm{C}=\mathrm{O})$ stanching vibration & Increasing \\
\hline & 1623 & 1623 & 1623 & $(\mathrm{C}=\mathrm{C})$ stanching vibration in dines & Increasing \\
\hline & 1539 & 1539 & 1539 & & \\
\hline & 1483 & --- & 1483 & $(\mathrm{C}=\mathrm{C})$ stretching of aromatic & New band \\
\hline & 1116 & 1116 & 1118 & $(\mathrm{C}-\mathrm{O})$ stanching vibration & Decreasing \\
\hline & 1106 & 1106 & 1106 & & Increasing \\
\hline & 830 & 830 & 835 & Conjugated double bond & Increasing \\
\hline & 758 & 758 & 758 & $(=\mathrm{C}-\mathrm{H})$ stretch vibration & Increasing \\
\hline \multirow{13}{*}{ PVBP $+10.0 \%$ DET } & 3857 & --- & 3857 & $(\mathrm{O}-\mathrm{H})$, stretching vibration & Decreasing \\
\hline & 3741 & 3741 & 3743 & $\mathrm{C}-\mathrm{O}-\mathrm{C}$ stretching vibration & Increasing \\
\hline & 3441 & 3441 & 3446 & $(\mathrm{OH})$, stretching vibration of carboxylic acid & Increasing \\
\hline & 3030 & 3030 & 3032 & $(=\mathrm{C}-\mathrm{H})$, stretching vibration of Aromatic & Increasing \\
\hline & 2924 & 2924 & 2926 & $(\mathrm{C}-\mathrm{H})$, stretching vibration of benzene & Increasing \\
\hline & 2845 & 2845 & 2847 & $(\mathrm{O}-\mathrm{H})$ stanching vibration & Increasing \\
\hline & 1721 & 1721 & 1726 & $(\mathrm{C}=\mathrm{O})$ stanching vibration & \\
\hline & 1618 & 1618 & 1623 & $(\mathrm{O}-\mathrm{H})$ stanching vibration & Increasing \\
\hline & 1480 & 1480 & 1485 & $(\mathrm{C}=\mathrm{C})$ stanching vibration in dines & Increasing \\
\hline & 1234 & 1234 & 1236 & $(\mathrm{C}=\mathrm{C})$ stretching of aromatic & Increasing \\
\hline & 1111 & 1111 & 1116 & $(\mathrm{C}-\mathrm{O})$ stanching vibration & Decreasing \\
\hline & 825 & 825 & 835 & Conjugated double bond & Increasing \\
\hline & 753 & 753 & 758 & $(=\mathrm{C}-\mathrm{H})$ stretch vibration & Decreasing \\
\hline
\end{tabular}

position as observed in polystyrene spectrum [44]. The increase in absorption intensity for the bands $1412 \mathrm{~cm}^{-1}, 1090 \mathrm{~cm}^{-1}$ and $1074 \mathrm{~cm}^{-1}$ in blended films in comparison with that of pure PVBP films, indicates that there is an increase in the number of $(C=C)$ that resulted from hydrogen abstraction during chainsscission process. The presence of the absorption band at $825 \mathrm{~cm}^{-1}$, may suggest that the formation of conjugated double bond sequences in the main polymer chain.

As can be seen from Table 4 and Table 5, many FT-IR absorption bands increase their intensities, other decrease their intensities while some new bands appeared in irradiated blended PVBP films, and these changes increases with 
increase in amount of added plasticizers and with the increase in molar mass of the used plasticizers. These changes correlate well with obtained for thermal degradation of plasticized poly (para-substituted styrene) solid films [1] [4]. The trend of increase in the efficiency of photo-degradation was found, DOT > DET > DMT. Phthalate plasticizers, DOP and DBP showed higher efficiency of photo quenching than what was obtained by terephthalate plasticizers. This behavior may indicate that there is higher stability for the [terephthalate-PVBP] ${ }^{*}$ excited complex than that of $[\text { phthalate- } P V B P]^{*}$ excited complex.

It was reported by Szarka et al, that the thermo-oxidation of plasticization of poly (vinyl chloride) (PVC) in dioctyl phthalate (DOP), showed an increase in degradation process. Thermo-oxidation leads to PVCs with certain extent of internal plasticization by DOP chemically bound to the PVC chains and by the oxidized chain segments as well. The added plasticizer can also degrade during photo-oxidation and forming free radicals. The resulting radicals can combine with the polymeric radicals, and thus the plasticizers can be chemically bound to the polymer chain [49] [50], and hence accelerate the photogegradation processes in blended polymeric matrix.

\subsubsection{FT-IR Spectra from (2500 to $4000 \mathrm{~cm}^{-1}$ )}

As can be noticed from Figures 9-11 and Tables 3-5, modifications also noticed in various absorption bands in the FT- IR spectra in the region (2500 - 4000 $\mathrm{cm}^{-1}$ ), of pure and blended PVBP films with $10.0 \%(\mathrm{wt})$ plasticizers, upon irradiation for $120 \mathrm{~min}$. The $F T-I R$ spectra for irradiated pure and blended PVBP films with phthalate and terephthalate plasticizers show an increase in the hydroxyl stretching vibration region $\left(3500-3300 \mathrm{~cm}^{-1}\right)$. Also it shows a decrease in the absorption intensity of a broad band centered at $3445 \mathrm{~cm}^{-1}$, associated with carboxylic acid. The absorption bands at $3851 \mathrm{~cm}^{-1}$ and $3743 \mathrm{~cm}^{-1}$, are also responsible for the formation of aliphatic hydroperoxide [19]. The region (2800 $3100 \mathrm{~cm}^{-1}$ ) shows three main bands at $3032 \mathrm{~cm}^{-1}, 2924 \mathrm{~cm}^{-1}$, and $2837 \mathrm{~cm}^{-1}$, which are attributed to the deformation and skeletal vibration of $(\mathrm{C}-\mathrm{H})$ in pure and blended poly (4-vinylbiphenyl) films.

The FT-IR absorption spectra of blended PVBP with 10\% DOT, DET, DMT, DBP and DOP, show an increase in the intensity of many absorption bands. These bands were assigned to the formation of more conjugated double bonds as well as the formation of carbonyl containing compounds. It is more likely that plasticizer molecule initiate free radicals-photochemical reactions that accelerate the photodegradation and photo-oxidation process.

\subsubsection{FT-IR Spectra from (1000 to $\left.2500 \mathrm{~cm}^{-1}\right)$}

As can be noticed from Figures 9-11, and Tables 3-5, modifications also noticed in various absorption bands in the FT-IR spectra in the region (1000 - 2500 $\mathrm{cm}^{-1}$ ). It showed the appearance of the absorption band at $1721 \mathrm{~cm}^{-1}$, that associated with the formation of carbonyl compounds resulted from the photodegradation of polymeric chains. However, the interpretation of this band is not 
simple because of the overlapping of the different types of carbonyl species in the same frequency range. It is generally accepted to attribute the absorption band for $(\mathrm{C}=\mathrm{O})$ stretching vibration at $\left(1740-1720 \mathrm{~cm}^{-1}\right)$, to saturated and unsaturated ketones and aldehydes [45] [48]. The increase in the intensity of the absorption bands at $\left(1626 \mathrm{~cm}^{-1}, 1593 \mathrm{~cm}^{-1}\right.$ and $\left.1485 \mathrm{~cm}^{-1}\right)$ can also be attributed either to the $(\mathrm{C}=\mathrm{O})$ stretching vibration of aromatic ketones, or to the stretching vibration of the substituted benzene ring [8]. The other increase in the intensities of the absorption bands of $\left(1236 \mathrm{~cm}^{-1}, 1101 \mathrm{~cm}^{-1}\right.$ and $\left.1056 \mathrm{~cm}^{-1}\right)$ indicates an increase in the $(\mathrm{C}-\mathrm{O})$ stretch vibration of formed alcoholic compounds during photo-degradation of polymeric chains [43] [44], or to the $(\mathrm{C}=\mathrm{C})$ stretching of aromatic conformations resulted from the photodegradation process [47].

\subsubsection{FT-IR Spectra from ( 500 to $1000 \mathrm{~cm}^{-1}$ )}

At low region of the $F T-I R$ absorption spectra of pure and blended PVBP films at the region $\left(500-1000 \mathrm{~cm}^{-1}\right)$, as in Figures 9-11, which shows an increase in the intensities of many absorption bands at $\left(825 \mathrm{~cm}^{-1}, 753 \mathrm{~cm}^{-1}\right.$ and $\left.536 \mathrm{~cm}^{-1}\right)$. The increase in the intensity of these bands upon the increase in irradiation time and in the added amount of plasticizers, indicate the presence of photo-degradation in polymeric chains. The absorption band at $\left(825 \mathrm{~cm}^{-1}\right)$, was also observed in the spectra of irradiated blended polymer films, which can suggests the formation of conjugated double bond sequences in the main polymer chains. The same band was observed by Grassie and Weir on photo-oxidation of polystyrene [6] [8].

From the FT-IR spectra of irradiated and non-irradiated pure and blended PVBP films, modifications occur in different regions of the Spectra, which permit characterizing these modifications in the following points:

1) At high region of the FT-IR spectra, the absorption band at $3440 \mathrm{~cm}^{-1}$, showed a noticeable decrease in pure and blended polymer. On the other hand, a very small decrease was observed in the irradiated polymer that can be ascribed to associate carboxylic acid group [45].

2) In the domain of the $(\mathrm{C}=\mathrm{O})$ stretching vibrations (Figures 9-11) of pure and blended PVBP irradiated films, one can observes the increase in the intensity of the band at about $1721 \mathrm{~cm}^{-1}$, indicating the formation of carbonyl compounds resulted from the degradation of polymeric structures.. The increase in the intensity of the band at $1645 \mathrm{~cm}^{-1}$, may well indicate that aromatic units lose their symmetry throughout the photo-oxidation process.

3) The formation of broad band between $\left(2800 \mathrm{~cm}^{-1}\right.$ and $\left.3050 \mathrm{~cm}^{-1}\right)$, with three breaded shoulders at $3021 \mathrm{~cm}^{-1}, 2924 \mathrm{~cm}^{-1}$ and $2854 \mathrm{~cm}^{-1}$, assigned to the $(\mathrm{C}-\mathrm{H})$, stretching vibration of benzene and $(\mathrm{O}-\mathrm{H})$ stanching vibration, and was found to increase in their intensity with the increase of irradiation time. Such observation suggests that the photodegradation process involves the oxidation of benzene rings [7].

4) In the complex region of the $(\mathrm{C}-\mathrm{O})$ stretch and $(\mathrm{C}-\mathrm{O}-\mathrm{H})$ bend vibrations, an increase in the intensity of the absorbance is observed throughout the increase in irradiation times of the polymer, which becomes higher in the case of 
blended polymer films. Well-defined maxima appear in the spectra, as shown in Table 3 and Table 4. Major increases at $1455 \mathrm{~cm}^{-1}$, and $1114 \mathrm{~cm}^{-1}$ could suggest the formation of mono-substituted benzene rings [7] [9].

5) The presence of the absorption band at $825 \mathrm{~cm}^{-1}$, as can be seen in Figures 9-11, may suggest the formation of conjugated double bond sequences in the main polymer chain during the irradiation process.

\section{Conclusions}

1) The irradiation of pure and blended PVBP films with different amount of added phthalate and terephthalate plasticizers in presence of air increases the photo-degradation of irradiated PVBP films. The efficiency of photo degradation was found to increase with the increase in the bulkiness of used plasticizer, and this can cause a decrease in the stability of the energy transfer complex between polymer structure and the added plasticizer molecule.

2) The irradiation process to pure and blended PVBP films at $288 \mathrm{~nm}$ resulted in a decrease in the intensity of excimer fluorescence, changes in the shape of the fluorescence spectra and a small increase in the red shift of the fluorescence band maxima. This indicates that absorbed light energy caused photodegradation of polymeric chains and was accelerated by the presence of air.

3) Irradiation of blended polymeric films showed an increase in the intensity of the FT-IR absorption bands with the increase in the amount of added plasticizer, and an increase in the intensity of a new absorption bands at about (1645, and $1714 \mathrm{~cm}^{-1}$ ). This indicates the formation of carbonyl compounds resulted from the photo-oxidation of polymeric structures. The increase in other FT-IR bands, at $3021 \mathrm{~cm}^{-1}, 2924 \mathrm{~cm}^{-1}, 2854 \mathrm{~cm}^{-1}, 1623 \mathrm{~cm}^{-1}, 1539 \mathrm{~cm}^{-1}$ and $1483 \mathrm{~cm}^{-1}$, $1106 \mathrm{~cm}^{-1}, 830 \mathrm{~cm}^{-1}$ and $758 \mathrm{~cm}^{-1}$ could suggest that irradiation of polymeric films caused s destruction of polymeric chains and produces different photoproducts.

4) The decrease in the intensity of the absorption band at $3441 \mathrm{~cm}^{-1}$ with the increase in irradiation time for pure and blended polymer films indicates that the decrease in aromacity of the polymer chromophores through the oxidation of benzene ring and the formation of carboxylic acids group [41].

5) According to the obtained results on the photo-oxidation of PVBP films, chain scissions are the initial degradation process and were enhanced by plasticization. Polymers degradation is normally affected by light energy as well as by thermal heating by the environment. It is important for future study is the use these combined techniques to obtain data on the analysis of the nature of photoproducts resulted from the degradation process, and to conclude the type of mechanism of degradation. Thermal degradation of PVBP films is under investigations, and will be reported shortly.

\section{References}

[1] Bertini, F., Audisio, G. and Kiji, J. (1995) Thermal Degradation of Chlorinated Polystyrenes. Journal of Analytical and Applied Pyrolysis, 28, 205-217. https://doi.org/10.1016/0165-2370(93)00774-H 
[2] Lucas, P.C. and Porter, R.S. (1989) Auto Inhibition in Polystyrene Photo-Oxidtion. Polymer Degradation and Stability, 26, 203-208. https://doi.org/10.1016/0141-3910(89)90073-6

[3] Ranby, B. and Rabek, J.F. (1974) Studies on the Photo-Oxidation Mechanism of Polymers. I. Photolysis and Photo-Oxidation of Polystyrene. Journal of Polymer Science, Polymer, Chemistry Edition, 12, 273-294. https://doi.org/10.1002/pol.1974.170120203

[4] Torikai, A., Takeuchi, A. and Fueki, K. (1986) The Effect of Temperature on the Photodegradation of Polystyrene. Polymer Degradation and Stability, 14, 367-375. https://doi.org/10.1016/0141-3910(86)90040-6

[5] Weir, N.A. (1978) Reactions of Hydroxyl Radical with Polystyrene. European Polymer Journal, 14, 9-14. https://doi.org/10.1016/0014-3057(78)90144-1

[6] Stivala, S.S., Kimum, J. and Reich, L. (1983) Degradation and Stability of Polymers. In: Jellinek, H.G., Ed., Aspects of Degradation and Stabilization of Polymers, Elsevier, Amsterdam, 1-66.

[7] Bera, M., Rivaton, A., Gandon, G. and Gardette, J.L. (2000) Photo-Oxidation of Poly (P-Xylene). European Polymer Journal, 36, 1753-1764.

https://doi.org/10.1016/S0014-3057(99)00258-X

[8] David, C., Baeyens-Volant, D., Delaunois, G., Lu-Vinh, Q., Piret, W. and Geuskens, G. (1978) Photo-Oxidation of Polymers-III Molecular Weight Changes in the Photolysis and Photooxidation of Polystyrene. European Polymer Journal, 14, 501-507. https://doi.org/10.1016/0014-3057(78)90037-X

[9] Al Ani, K.E. and Ramadhan, A.E. (2008) Photodegradation of Plasticized Poly (Para-Substituted Styrene) in Solution. Polymer Degradation and Stability, 93, 1590-1596. https://doi.org/10.1016/j.polymdegradstab.2008.04.010

[10] Al Ani, K.E. and Ramadhan, A.E. (2010) Study of the Influence of UV-Irradiation on the Photodegradation of Plasticized Poly (Para-Tert-Butylstyrene) Films. International Journal of Material Research, 101, 1554-1562. https://doi.org/10.3139/146.110434

[11] White, K.R. and Shyichuk, A.V. (2007) Effect of Stabilization on Scission and Cross-Linking Rate Changes during Photo-oxidation of Polypropylene. Polymer Degradation and Stability, 92, 2095-2101. https://doi.org/10.1016/j.polymdegradstab.2007.07.013

[12] Mailhot, B. and Gardette, J.L. (1992) Polystyrene Photo-Oxidation-1: Identification of the IR-Absorbing Photoproducts Formed at Short and Long Wavelength. Macromolecules, 25, 4119-4126. https://doi.org/10.1021/ma00042a012

[13] Allen, N.S. and Edge, M. (1992) Fundamentals of Polymer Degradation and Stability. Elsevier Applied Science Publishing LTD.

[14] Tamai, T., Hashida, I., Ichinose, N., Kawanishi, S., Inoue, H. and Mizuno, K. (1996) UV-Irradiation of Thin Film of Polystyrene Derivatives: Formation of Carboxylic Group and Cross-Linking from 4-Trimethylsilylmethyl Substituent. Polymer, 37, 5525-5528. https://doi.org/10.1016/S0032-3861(96)00438-7

[15] Geuskens, G., Bastin, P., Lu-Vinh, Q. and Rens, M. (1981) Photo-Oxidation of Polymers: Part IV-Influence of the Processing Conditions on the Photo-Oxidation Stability of Polystyrene. Polymer Degradation and Stability, 3, 295-306. https://doi.org/10.1016/0141-3910(81)90025-2

[16] Geuskens, G., Baeyens-Volant, D., Delaunois, G., Lu-Vinh, Q., Piret, W. and David, C. (1978) Photo-Oxidation of Polymers-I: A Quantitative Study of the Chemical Reactions Resulting from Irradiation of Polystyrene at $253.7 \mathrm{~nm}$ in the Presence of Oxygen. European Polymer Journal, 14, 291-297. 
https://doi.org/10.1016/0014-3057(78)90051-4

[17] Tse, K.C., Ng, F.M. and Yu, K.N. (2006) Photo-Degradation of DAVC by UV-Radiation at Various Wavelengths. Polymer Degradation and Stability, 91, 2380-2388. https://doi.org/10.1016/j.polymdegradstab.2006.03.017

[18] McNeill, C. and Coskun, M. (1987) Structure and Stability of Halogenated Polymers: Part 2-Chain-Chlorinated Polystyrene. Polymer Degradation and Stability, 18, 213-224. https://doi.org/10.1016/0141-3910(87)90002-4

[19] Al Ani, K.E. and Ramadhan, A.E. (2010) Plasticization Effect on the Photodegradation of Poly (4-Chlorostyrene) and Poly (4-Bromostyrene) Films. Materials Sciences and Applications, 1, 358-368. https://doi.org/10.4236/msa.2010.16052

[20] Weir, N.A. and Milkie, T.H. (1979) Photochemistry of Ring-Substituted Polystyrenes. II. Photolysis of Poly ( $p$-Fluoro, $p$-Chloro, and $p$-Bromostyrene). Journal of Polymer Science: Polymer Chemistry Edition, 17, 3735-3749. https://doi.org/10.1002/pol.1979.170171129

[21] Al Ani, K.E. and Anabtawi, M. (2012) UV-Irradiation Effect on the Photodegradation of Plasticized Poly (Ortho, Meta and Para-Fluorostyrene) Isomers in Solid Films. International Journal of Chemistry, 4, 62-84. https://doi.org/10.5539/ijc.v4n5p62

[22] Rosenberg, R.A., Simons, J.K., Chen, J.M. and Taylor, J.W. (1993) Fluorescence Studies of the Vacuum Ultraviolet, Synchrotron Radiation-Induced Photochemistry of Polystyrene. Macromolecules, 26, 3262-3266. https://doi.org/10.1021/ma00065a003

[23] Al Ani, K.E., Ramadhan, A.E. and Al Sieadi, W.N. (2015) Fourier-Transformation Inferred Spectroscopic Study of Plasticization Effects on the Photodegradation of Poly (Ortho, Meta, and Para-Fluorostyrene) Isomers Films. Journal of Vinyl and Additives Technology.

[24] Al Ani, K.E., Ramadhan, A.E. and Anabtawi, M. (2014) Irradiation Effect on Stability of Plasticized Poly (Fluorostyrene) Isomers in Solution. International Journal of Photochemistry, 1, 1-12. https://doi.org/10.1155/2014/536068

[25] Weir, N.A., Kutok, P. and Whiting, K. (1989) Some Aspects of the Long-Wave Photo-Oxidation of Polystyrenes. Polymer Degradation and Stability, 24, 247-256. https://doi.org/10.1016/0141-3910(89)90035-9

[26] Wypych, G. (2012) Handbook of Plasticizers. 2nd Edition, Chapter 12, Chem Tec Publishing, Toronto.

[27] Torikai, A., Takeuchi, T. and Fueki, K. (1983) Photodegradation of Polystyrene and Polystyrene Containing Benzophenone. Polymer Photochemistry, 3, 307-320. https://doi.org/10.1016/0144-2880(83)90038-6

[28] Kowal, J. and Nwakowska, M. (1982) Photo-Oxidation of Polystyrene in Dichloromethane Solvent. Polymer, 23, 281-282.

https://doi.org/10.1016/0032-3861(82)90316-0

[29] Subramanian, K. (2002) Photodecomposition of Poly (Styrene Peroxide). European Polymer Journal, 38, 1167-1173. https://doi.org/10.1016/S0014-3057(01)00297-X

[30] Al Ani, K.E. and Hawi, M.A. (2009) Effect of Plasticization on the Photodegradation of Poly (Para-Methoxystyrene) Films. Journal of Material Science, 44, 2674-268. https://doi.org/10.1007/s10853-009-3350-x

[31] Afrah, E.R. (2015) Effects of Added Phthalate Plasticizers on Photodegradation of Irradiated Poly ( $\alpha$-Methylstyrene) Films. Journal of Polymer Engineering, 35, 159-167. 
[32] Al Safi, S.A., Mouamin, M.T., Al Sieadi, W.N. and Al Ani, K.E. (2014) Irradiation Effect on Photodegradation of Pure and Plasticized Poly (4-Methylstyrene) in Solid Films. Materials Sciences and Applications, 1, 358-368.

[33] Torikai, A., Kobatake, T., Okisaki, F. and Shuyama, H. (1995) Photodegradation of Polystyrene Containing Flame-Retardant Wavelength Sensitivity and Efficiency of Degradation. Polymer Degradation and Stability, 50, 261-267. https://doi.org/10.1016/0141-3910(95)00143-3

[34] Choi, W.M., Jung, I.D., Sik, C. and Cho, W. (1998) Syntheses and Properties of Photodegradable Polystyrene-Containing Carbonyl Group. Journal of Applied Polymer Science, 67, 1237-1242. https://doi.org/10.1002/(SICI)1097-4628(19980214)67:7<1237::AID-APP11>3.0.CO $\underline{; 2-\mathrm{Z}}$

[35] Kaczmarek, H. (1995) Photodegradation of Polystyrene and Poly (Vinyl Acetate) Blends-I. Irradiation of PS/PVAc Blends by Polychromatic Light. European Polymer Journal, 31, 1037-1042. https://doi.org/10.1016/0014-3057(95)00094-1

[36] Tovborg Jensen, J.P. and Kops, J.J. (1981) Energy Transfer in Connection with the Photo-Oxidation of Polystyrene and Its Blends with Poly (2, 6-Dimethyl-1, 4-Phenylene Oxide). Journal of Polymer Science: Polymer Chemistry Edition, 19, 2765-2771. https://doi.org/10.1002/pol.1981.170191112

[37] Kaczmarek, H. (1995) Photodegradation of Polystyrene and Poly (Vinyl Acetate) Blends. II. Irradiation of PS/PVAc Blends by Fluorescent Lamp. European Polymer Journal, 31, 1175-1184. https://doi.org/10.1016/0014-3057(95)00095-X

[38] Kuzina, S.I. and Mikhailov, A.I. (2001) Photo-Oxidation of Polymers 4. The Dual Mechanism of Polystyrene Photo-Oxidation: A Hydroperoxide and a Photochain One. European Polymer Journal, 37, 2319-2325. https://doi.org/10.1016/S0014-3057(01)00028-3

[39] Weir, N.A. and Whiting, K. (1989) Initial Steps in the Photolysis and Photo-Oxidation of Polystyrene. European Polymer Journal, 25, 291-295. https://doi.org/10.1016/0014-3057(89)90234-6

[40] Kwon, J.H., Shin, S., Kim, K.H., Cho, M.J., Kim, K.N., Choi, D.H. and Ju, B.K. (2009) Organic Thin Film Transistors using 6, 13-bis (tri-isopropylsilylethynyl) Pentacene Embedded into Polymer Binders. Applied Physics Letters, 94, Article ID: 013506.

[41] Al Ani, K.E. and Suleiman, A.M. (2007) Substituent Effect on Fluorescence Quenching of Polystyrene Derivatives by Polymeric Plasticizers. Journal of Photochemistry and Photobiology, A, Chemistry, 188, 177-184. https://doi.org/10.1016/j.jphotochem.2006.12.010

[42] Al Ani, K.E. and Ramadhan, A.E. (2015) Kinetic Study of Photodegradation of Plasticized Polystyrene in Solid Films. Materials Sciences and Applications Journal, 6, 617-633.

[43] La Mantia, F.P. (1986) Influence of Processing Conditions on the Photo-Oxidation of Polystyrene Films. Polymer Degradation and Stability, 15, 283-290. https://doi.org/10.1016/0141-3910(86)90075-3

[44] Zhang, Z.F., Hu, X.Z. and Luo, Z.B. (1996) Wavelength Sensitivity of Photo-Oxidation of Polypropylene. Polymer Degradation and Stability, 51, 93-97. https://doi.org/10.1016/0141-3910(95)00210-3

[45] Luengo, C., Allen, N.S., Edge, M., Wilkinson, A., Parellada, M., Barrio, J.A. and Santa, R. (2006) Photo-Oxidative Degradation Mechanisms in Styrene-EthyleneButadiene-Styrene (SEBS) Triblock Copolymer. Polymer Degradation and Stability, 91, 947-956. https://doi.org/10.1016/j.polymdegradstab.2005.06.017 
[46] Rabek, J.F. (1995) Polymer Photodegradation, Mechanisms and Experimental Methods. Chapman and Hall, London. https://doi.org/10.1007/978-94-011-1274-1

[47] Millan, M.D., Locklin, J., Fulghum, T., Baba, A. and Advincula, R.C. (2003) Polymer Thin Film Photodegradation and Photochemical Cross-Linking FT-IR Imaging Evanescent Waveguide Spectroscopy, and QCM Investigation. Polymer, 46, 5556-5568. https://doi.org/10.1016/j.polymer.2005.05.050

[48] Lactose, J., Carlson, D.J., Falicki, S. and Wiles, M.D. (1991) Polyethylene Hydroperoxide Decomposition Products. Polymer Degradation and Stability, 34, 309-323. https://doi.org/10.1016/0141-3910(91)90125-B

[49] Szarka, G., Domjan, A., Szakas, T. and Ivan, B. (2012) Oil from Poly (Vinyl Chloride): Unprecedented Degradative Chain Scission under Mild Thermooxidative Conditions. Polymer Degradation and Stability, 97, 1787-1793.

https://doi.org/10.1016/j.polymdegradstab.2012.06.005

[50] Szarka, G. and Ivan, B. (2013) Thermal Properties, Degradation and Stability of Poly (Vinyl Chloride) Predegraded Thermooxidative in the Presence of Dioctyl Phthalate Plasticizer. Journal of Macromolecular Science Part A Pure and Applied Chemistry, 50, 208-214. https://doi.org/10.1080/10601325.2013.742804 